Advance Journal of Food Science and Technology 14(3): 103-107, 2018

DOI:10.19026/ajfst.14.5843

ISSN: 2042-4868; e-ISSN: 2042-4876

(C) 2018 Maxwell Scientific Publication Corp.

Submitted: January 29, $2018 \quad$ Accepted: February 14, 2018

Published: April 25, 2018

\title{
Research Article \\ Evaluation of Proximate Composition and Sensory Attributes of Dark Chocolate Fortified with Wheat Germ
}

\author{
Khaled M. Al-Marazeeq \\ Al-Huson University College, Al-Balqa Applied University, Jordan
}

\begin{abstract}
The aim of this study is to characterize Dark Chocolate (DC) fortified with the Wheat Germ (WG) and to study the effect of standard storage for two months on sensorial properties. Preliminary studies showed that the best combination of WG is $10 \%$. Proximate analysis showed that protein and total minerals contents of dark chocolate significantly $(\mathrm{p} \leq 0.05)$ increased by the addition of WG, whereas fat content significantly $(\mathrm{p} \leq 0.05)$ decreased, moisture and total carbohydrates were $(\mathrm{p}>0.05)$ similar. As a result total calories gained from ingestion of dark chocolate decreased by $20.5 \mathrm{Cal} / 100 \mathrm{~g}$. Appearance and color sensory attributes were ranked as "like very much" for both control (DC) and 10\% added WG (GDC) treatments. Melt in mouth, texture, flavor, taste and overall acceptability were ranked as "like moderately" for GDC in comparison to "like very much" for DC. Storage for two months doesn't affect $(\mathrm{p}>0.05)$ all the sensory attributes. It can be concluded that $10 \%$ GDC can involve as a nourishing source to replace the DC as evidenced by their higher protein and minerals contents and its acceptance by the taste panel.
\end{abstract}

Keywords: Dark chocolate, fortification, proximate analysis, sensory evaluation, wheat germ

\section{INTRODUCTION}

Development of new food product using functional food ingredients has been increased worldwide by consumers for value adds food. Sensory evaluation is used as a tool for quality control purposes, product development and optimization of processes, as well as the understanding of consumer palatability towards a product. Moreover, in the marketing field, it enables large companies to develop new products (Norhayati and Ayob, 2014).

Sensory properties represent the most important parameters of chocolates and chocolate products, as consumers consume chocolate exclusively as a product for sensory satisfaction (taste, odor, flavor) and not as a general purpose foodstuff (Popov-Raljić et al., 2010).

Subsequent $16^{\text {th }}$ to early $20^{\text {th }}$ century manuscripts produced in Europe and New Spain revealed more than 100 medicinal uses for cacao/chocolate (Dillinger et al., 2000). Latif (2013) reviewed the human health of chocolate/cocoa; he illustrated that chocolate/cocoa is a rich source of antioxidants due to its large concentrations of flavonoids, epicatechin, catechin and, procyanidins. Cocoa mass also contains minerals such as potassium, phosphorus, copper, iron, zinc and magnesium.

Numerous studies have suggested many beneficial effects of cocoa in cardiovascular diseases, blood pressure lowering effects, significant vasodilatation by increasing serum nitric oxide levels, anti-diabetic effects, anti-stress effects, anti-obese effects, antitumor effects. It has been documented that chocolate supplementation before exercise results in rapid recovery of post-exercise physiological and metabolic changes.

Additional medical complaints treated with chocolate/cacao have included anemia, poor appetite, mental fatigue, poor breast milk production, consumption/tuberculosis, fever, gout, kidney stones, reduced longevity and poor sexual appetite/low virility (Dillinger et al., 2000).

White chocolate, however, differs from milk and dark chocolate through the absence of cocoa solids, which contain antioxidants and thus makes little or no contribution to the potential polyphenol-induced improvements in human health. Most dark chocolate contains higher amounts of antioxidant cocoa flavanols than does milk chocolate. A 40-g serving of milk chocolate, for example, provides $394 \mathrm{mg}$ of cocoa flavonoids, whereas dark chocolate contains $951 \mathrm{mg}$ (Engler and Engler, 2006).

Pereira et al. (2014) concluded that the daily ingestion of $8 \mathrm{~g} /$ day of $70 \%$ cocoa chocolate during a month improves the endothelial function of young people, improving the endothelium-dependent vasodilatation. Wong and Lua (2012) found that a 3- 
day dark chocolate consumption may reduce Anxiety and depressive symptoms and thus improved the healthrelated quality of life status in cancer patients.

Grassi et al. (2005) concluded that dark chocolate decreases blood pressure and improves insulin sensitivity in healthy persons. Petyaev et al. (2014) found that daily intake of lycopene-containing lycosome formulation of dark chocolate reduced the systemic blood pressure, as well as the total cholesterol and triglycerides in serum after the one month observational period in comparison to dark chocolate and lycopene ingested separately which did not affect serum lipids and systematic blood pressure.

On the other hand, wheat germ is a cheap byproduct produced during wheat milling industry. This byproduct characterizes by high contents of proteins, lipids, minerals, dietary fibers, unsaturated fatty acids, essential amino acids, total phenols and total flavonoids. Moreover, defatted wheat germ showed antioxidant and free radical scavenging activities in concentration-dependent manner which were close to that of the synthetic antioxidants, BHA and BHT (Abbas at al., 2015; Mahmoud et al., 2015; Youssef, 2015; Özcan et al., 2013).

Addition of $7 \%$ wheat germ to a high-fat cholesterol diet (20\% fat, $0.5 \%$ cholesterol) showed a beneficial effect on the lipid status of rats in comparison with a low-fat diet (3\% fat). Adding wheat germ to the high-fat cholesterol diet significantly increased the High-Density Lipoprotein (HDL) cholesterol and the HDL serum cholesterol ratio and lowered the Very Low-Density Lipoprotein (VLDL) triglycerides. Thus the lipoprotein pattern was comparable to that obtained with the low-fat diet. At the same time, triglyceride and cholesterol accumulation in the liver and the triglyceride content in skin were significantly decreased (Lairon et al., 1987).

Producing chocolates containing functional ingredients is a challenge especially in maintaining their sensory characteristics which generally lead to a decrease in consumers' acceptability (Norhayati and Ayob, 2014).

This study was carried out to investigate the level of Jordanian consumers' preference of dark chocolate produced with wheat germ and the proximate composition of this product, as well as the effect of storage for two months on the sensory attributes. This could be enabling chocolate companies to establish control activities and develop new products.

\section{MATERIALS AND METHODS}

Dark chocolate processing: Dark chocolate ingredients including cocoa liquor, cocoa butter, sugar and lecithin were purchased from local markets in Jordan, Wheat Germ (WG) was purchased from a governmental mill. For control dark chocolate $47.5 \%$ sugar, $40 \%$ cocoa liquor, $12 \%$ cocoa butter and $0.5 \%$ lecithin were mixed together using gentle heating. After homogenization of the mixture the chocolate was molded using plastic molds of about $8 \mathrm{~g} / \mathrm{cube}$ and then the prepared chocolate cubes were left to cool and solidify at room temperature.

Preliminary study and final treatments preparation: The preliminary study was carried out to adjust the highest sensory acceptable level of the added wheat germ to dark chocolate. Blends were carried out using different concentrations of both intact and ground wheat germ $(6-15 \% \mathrm{w} / \mathrm{w})$. Then the prepared dark chocolate cubes were evaluated organoleptically by five trained panelists chosen from the teaching staff of the Department of Nutrition and Food Technology, AlHuson University College. The samples were evaluated for overall acceptability using a 9-hedonic scale test as described by Larmond (1991). The highest sensory acceptable level of the added wheat germ was optimized at $10 \%(\mathrm{w} / \mathrm{w})$. Accordingly, 10\% (W/W) WG was added to the dark chocolate formula. A control negative treatment was prepared at zero level of WG to conduct subsequent comparisons. Control Dark Chocolate (DC) and dark chocolate with 10\% WG (GDC) cubes were enwrapped using aluminum foil and kept at room temperature for further analyses.

Proximate analysis: DC and GDC treatments were analyzed for proximate analysis including moisture, fat, protein and ash following AOAC (2000) procedures. Analyses were carried out in duplicate. Total carbohydrates were measured by the difference.

Sensory evaluation: Sensory characteristics were evaluated at zero time and after two months of storage at room temperature by 30 panelists chosen from the teaching staff, graduated students and technicians of the Department of Nutrition and Food Technology, AlHuson University College. The panelists were from both genders, with 19-50 years old. The samples were evaluated for appearance, color, melt in mouth, texture, flavor, taste and overall acceptability, using 9-hedonic scale test as described by Larmond (1991), where score 9 , represents "like extremely" and score 1 represents "dislike extremely".

Statistical analysis: Data were statistically analyzed, where standard deviation, means and ANOVA followed by Multiple Comparisons at $\alpha=0.05$ were determined using Statistical Package for Social Science (SPSS version 19, SPSS (2010)).

\section{RESULTS AND DISCUSSION}

Preliminary study and final treatments preparation: Overall acceptability of dark chocolate preliminary blends with intact as well as ground wheat germ (Table 1) showed that treatments with $6-10 \%$ intact $\mathrm{WG}$ were 
Adv. J. Food Sci. Technol., 14(3): 103-107, 2018

Table1: Overall acceptability of the preliminary dark chocolate treatments with added wheat germ $\%$ *

\begin{tabular}{|c|c|c|c|c|c|}
\hline Treatments & $6 \%$ & $8 \%$ & $10 \%$ & $12 \%$ & $15 \%$ \\
\hline Chocolate with intact WG & $7.8^{\mathrm{a}}$ & $7.6^{\mathrm{a}}$ & $7.4^{\mathrm{a}}$ & $6.1^{b}$ & $4.7^{\mathrm{d}^{* * *}}$ \\
\hline Chocolate with ground WG & $5.5^{\mathrm{c}}$ & $4.2^{\mathrm{d}}$ & $3.7^{\mathrm{e}}$ & $3.0^{\mathrm{f}}$ & $2.1^{\mathrm{g}}$ \\
\hline
\end{tabular}

*Readings were presented as an average of five panelists; ** Significant differences at $\alpha=0.05$ between chocolate with intact and ground WG

Table2: Proximate analysis of dark chocolate treatments*

\begin{tabular}{lll}
\hline Characteristics\% & DC & GDC \\
\hline Moisture & $6.2^{\mathrm{a}}$ & $6.8^{\mathrm{a}^{* *}}$ \\
Protein & $5.6^{\mathrm{b}}$ & $7.5^{\mathrm{a}}$ \\
Fat & $31.3^{\mathrm{a}}$ & $28^{\mathrm{b}}$ \\
Ash & $2.7^{\mathrm{b}}$ & $3.1^{\mathrm{a}}$ \\
Total carbohydrates & $54.2^{\mathrm{a}}$ & $54.6^{\mathrm{a}}$ \\
\hline
\end{tabular}

*Readings were presented as an average of duplicates; ** Significant differences at $\alpha=0.05$ between DC and GDC; DC: control dark chocolate; GDC: dark chocolate with added $10 \%$ wheat germ

Table3: Sensory characteristics evaluation average of dark chocolate treatments *

\begin{tabular}{|c|c|c|c|}
\hline Characteristics & DG & GDC & GDC 2 months \\
\hline Appearance & $8.4^{\mathrm{a}}$ & $8.2^{\mathrm{a}}$ & $8.0^{\mathrm{a}^{* *}}$ \\
\hline Color & $8.3^{\mathrm{a}}$ & $8.1^{\mathrm{a}}$ & $8.1^{\mathrm{a}}$ \\
\hline Melt in mouth & $8.0^{\mathrm{a}}$ & $7.2^{\mathrm{b}}$ & $7.5^{b}$ \\
\hline Texture & $8.3^{\mathrm{a}}$ & $7.1^{\mathrm{b}}$ & $7.4^{b}$ \\
\hline Flavor & $8.5^{\mathrm{a}}$ & $7.3^{\mathrm{b}}$ & $7.1^{\mathrm{b}}$ \\
\hline Taste & $7.8^{\mathrm{a}}$ & $7.0^{\mathrm{b}}$ & $6.8^{b}$ \\
\hline Overall acceptability & $8.2^{\mathrm{a}}$ & $7.2^{\mathrm{b}}$ & $7.1^{\mathrm{b}}$ \\
\hline
\end{tabular}

attributed as the best blends that ranged within the category of "like moderately", as the added WG increased higher than $10 \%$ the overall acceptability attribute decreased from "like slightly" to "dislike slightly". On the other hand, all treatments with added ground WG had lower attributes than intact ones ranged from "neither like nor dislike" to "dislike very much".

Although reduction particle size of the chocolate solid non-fat constituents increases the smooth feeling on the tongue when chocolate melts in the mouth (Beckett, 2008), added of ground WG to dark chocolate had negative attributes in comparison to intact WG. Therefore, the treatment optimized to end up with $10 \%$ intact $W G$ addition.

Proximate composition of dark chocolates: Proximate analysis of DC and GDC treatments, as shown in Table 2, indicated that protein and ash contents significantly $(\mathrm{p} \leq 0.05)$ increased in dark chocolate by addition of WG which is due to high contents of these two valuable constituents in WG as found in our study (Al-Marazeeq et al., 2017). Fat significantly $(\mathrm{p} \leq 0.05)$ decreased by the addition of $10 \%$ WG from $31.3 \%$ to $28 \%$, while moisture and total carbohydrates contents not significantly $(p>0.05)$ changed.

Calculating the energy value (Cal) of the samples, by adding crude protein and total carbohydrates multiplied by four $(\mathrm{Cal} / \mathrm{g})$ added to the total lipid content multiplied by factor nine $(\mathrm{Cal} / \mathrm{g})$, showed that the energy value could be gained from DC is 520.9 $\mathrm{Cal} / 100 \mathrm{~g}$, while the energy value could be gained from GDC is $500.4 \mathrm{Cal} / 100 \mathrm{~g}$ with a reduction of 20.5 $\mathrm{Cal} / 100 \mathrm{~g}$ dark chocolate, this mainly due to reduction of fat content and increment in protein of GDC as shown in Table 2 . This reduction of energy value could be beneficial from the nutritional point of view.

Sensory evaluation: Results of the sensory evaluation in terms of appearance, color, melt in mouth, texture, flavor, taste and overall acceptability for both DC and $10 \%$ GDC samples at zero time and after two months of storage at room temperature using 9-hedonic scale are shown in Table 3.

There were no significant differences $(\mathrm{p}>0.05)$ regarding appearance and color between all treatments which were evaluated as "like very much". From the consumer's point of view, chocolate and chocolate products must have attractive appearance including color, surface brightness and form (Popov-Raljić et al., 2010).

Melt in mouth, texture, flavor, taste and overall acceptability attributes decreased significantly $(\mathrm{p} \leq 0.05)$ from "like very much" for DC to "like moderately" by addition of $10 \% \mathrm{WG}$ to dark chocolate but remained to acquire high evaluation attributes that could be very acceptable by consumers. Sensory properties represent the most important parameters of chocolates and chocolate products, as consumers consume chocolate exclusively as a product for sensory satisfaction (taste, odor, flavor) and not as a general purpose foodstuff (Popov-Raljić et al., 2010).

Chocolate is solid at normal room temperatures yet melts easily within the mouth. This is because the main fat in it, which is called cocoa butter, is essentially solid at temperatures below $25^{\circ} \mathrm{C}$ when it holds all the solid sugar and cocoa particles together. This fat, however, is almost entirely liquid at body temperature, enabling the 
particles to flow past one another, so the chocolate becomes a smooth liquid when it is heated in the mouth (Beckett, 2008). Remaining of wheat germ particles of GDC sample over the tongue after complete melting of other dark chocolate constituents could be the responsible about the difference of "melting in mouth" attribute by panelists, but still having well acceptable palatability.

Firmness at ambient temperature, regular break, unique flavor-taste and odor and satisfactory shelf life during storage and distribution, all are very important sensory parameters of chocolate by consumers (PopovRaljić et al., 2010). As shown from Table 3 the texture, flavor and taste attributes of GDC were evaluated in the range of "like moderately" by the panelists, indicating acceptable sensory characteristics of dark chocolate by adding of $10 \%$ wheat germ. Overall acceptability of GDC attribute indicating that producing of dark chocolate with $10 \%$ added wheat germ could be acceptable from consumers' point of view.

Storage time for two months at room temperature didn't affect all sensory parameters of GDC evaluated by panelists, which could be beneficial from the production point of view to manufacturing a stable dark chocolate product by adding of $10 \%$ wheat germ.

\section{CONCLUSION}

Fortification of dark chocolate with wheat germ increased its protein and total minerals contents, while decreased fat content. The optimal fortification level is recommended to be $10 \%$ as it was proved to be ranked as the best combination from the sensory point of view. Therefore, we recommended production of dark chocolate with the addition of this valuable and cheap byproduct (wheat germ) to gain more functional and nutritional benefits.

Further studies are recommended to evaluate the ingestion effect of this fortified dark chocolate with wheat germ on human health, such as its effect on cardiovascular system, endothelial function, vascular function, insulin sensitivity, obesity, antioxidant properties and other nutritional and health properties.

\section{REFERENCES}

Abbas, H.M., A.M.S. Hussein, F.L.Seleet, H.M.Bayoumi and M. Abd El-Aziz, 2015. Quality of some dairy by-products supplemented with wheat germ as functional beverages. Int. J. Dairy Sci., 10: 266-277.

Al-Marazeeq, K., M.A.Abdulluh and M. Angor, 2017. Characterization and sensory evaluation of pomegranate molasses fortified with wheat germ. Ad. J. Food Sci. Technol., 13(4): 178-181.

AOAC, 2000. Association of Official Analytical Chemists. 17th Edn., A.O.A.C. International, Maryland, U.S.A.
Beckett, S., 2008. The History of Chocolate. 2nd Edn., The Royal Society of Chemistry, Cambridge, UK, pp: $1-525$.

Dillinger, T., P. Barriga, S. Escárcega, M. Jimenez, D. Lowe and L. Grivetti, 2000. Chocolate: Modern science investigates an ancient medicine. J. Nutr., 130: 2057S-2072S.

Engler, M.B. and M.M. Engler, 2006. The emerging role of flavonoid-rich cocoa and chocolate in cardiovascular health and disease. Nutr. Rev., 64: 109-118.

Grassi, D., C. Lippi, S. Necozione, G. Desideri and C. Ferri, 2005. Short-term administration of dark chocolate is followed by a significant increase in insulin sensitivity and a decrease in blood pressure in healthy persons. Am. J. Clin. Nutr., 81(03): 611614.

Lairon, D., C. Lacombe, P. Borel, G. Corraze, M. Nibbelink, M. Chautan, F. Chanussot and $\mathrm{H}$. Lafont, 1987. Beneficial effect of wheat germ on circulating lipoproteins and tissue lipids in rats fed a high fat, cholesterol-containing diet. J. Nutr., 117(5): 838-845.

Larmond, E., 1991. Laboratory Methods for Sensory Evaluation of Food. 2nd Edn., Canadian Department of Agriculture Publication, Ottawa.

Latif, R., 2013. Chocolate/cocoa and human health: A review. Neth. J. Med., 71(2): 63-68.

Mahmoud, A.A., A.A.A. Mohdaly and N.A.A. Elneairy, 2015. Wheat germ: An overview on nutritional value, antioxidant potential and antibacterial characteristics. Food Nut. Sci., 6: 265277.

Norhayati, H. and M.K.Ayob, 2014. Sensory quality of pilot-scale prebiotic chocolates in Malaysia. Sains Malaysiana, 43(9): 1333-1344.

Özcan, M.M., A. Rosa, M.A.Dessi, B. Marongiu, A. Piras and F.Y.I. AL-Juhaimi, 2013. Quality of wheat germ oil obtained by cold pressing and supercritical carbon dioxide extraction. Czech J. Food Sci., 31(3): 236-240.

Pereira, T., M. Vilas Boas and J. Conde, 2014. Dark chocolate intake improves endothelial function in young healthy people: A randomized and controlled trial. Cardiovasc. Syst., 2(3): 1-6.

Petyaev, I.M., P.Y. Dovgalevsky, N.E. Chalyk, V. Klochkov and N.H. Kyle, 2014. Reduction in blood pressure and serum lipids by lycosome formulation of dark chocolate and lycopene in prehypertension. Food Sci. Nutr., 2(6): 744-750.

Popov-Raljić, J.V., J.G. Laličić-Petronijević, A.S. Georgijev, V.S. Popov and M.A. Mladenović, 2010. Sensory evaluation of pralines containing different honey products. Sensors, 10(09): 79137933.

SPSS, 2010. Statistical Package for the Social Sciences. Version 19.0, IBM Corp, Armonk, NY. 
Wong, S.Y. and P.L. Lua, 2012. Effects of dark chocolate consumption on anxiety, depressive symptoms and health-related quality of life status among cancer patients. Health Env. J., 3(1): 27-35.
Youssef, H.M.K.E., 2015. Assessment of gross chemical composition, mineral composition, vitamin composition and amino acids composition of wheat biscuits and wheat germ fortified biscuits. Food Nutr. Sci., 6(10): 845-853. 